\title{
Brief Discussion on Cause, Prevention and Control for Roof Leakage on Industrial Buildings Mei-Di SHAN ${ }^{1, a, *}$, Feng ZHOU ${ }^{2, b}$ \\ ${ }^{1}$ China Tobacco Zhejiang Industrial Co., Ltd \\ ${ }^{2}$ China Tobacco Zhejiang Industrial Co., Ltd \\ a979248535@qq.com, bzfzhou@zjtobacco.com \\ ${ }^{*}$ Corresponding author
}

Keywords: Industrial Building, Roof Leakage, Form of Leakage, Cause of Leakage, Preventative Measures, Control Measures.

\begin{abstract}
Roof leakage has become a common problem on housing quality, which not only affects normal use of houses, and erodes the main structure of buildings, but brings about great challenge to infrastructure maintenance and seriously shortens service life of buildings. Starting with the common causes for roof leakage on large industrial buildings while combining with engineering practice, this paper discussed how to effectively prevent and control roof leakage on industrial buildings so as to reduce the significant harm brought with.
\end{abstract}

\section{Introduction}

During urban construction, especially construction of large industrial buildings, different forms of leakage will occur on buildings due to a variety of causes, e.g. design, materials, construction and external climate, etc. For the past few years, although various new waterproofing materials have appeared one after another, they are not widely used in our country yet because of the expensive cost, high construction requirements and their durability which needs to be further verified. Therefore, the problem of roof leakage has not been completely solved.

The discussion in this paper is based on a large industrial building project, a large Category-C comprehensive industrial building integrating production, temporary storage, auxiliary office for workshop with GFA of about $180,000 \mathrm{~m}^{2}$, building height of $23.6 \mathrm{~m}$, and roof waterproofing of Grade 2 by 2 courses 4 thick polyester felt Type-II SBS modified asphalt waterproofing rolls. The leakage frequently occurs on roof in recent years and it is hard to repair. Based on the common forms and causes of roof leakage on such industrial building, this paper proposed corresponding prevention and control measures to reduce the great harm of roof leakage.

\section{Analysis on Common Forms and Causes of Leakage on Industrial Buildings}

A lot of factors will possibly bring about the leakage, including design of building, quality of materials, construction technologies, competence of workers, external environment, later-stage service, etc. Now the paper moved on to the current situations of leakage on industrial buildings.

\section{Roof Leakage Due to Concrete}

The self-waterproofing by concrete floor slabs of industrial buildings is of great importance for roof waterproofing. Firstly, the construction of roof concrete is usually divided into several stages, and the leakage might easily occur in later stage if the construction joint is not properly treated; secondly, if the concrete is insufficiently or incompletely vibrated during pouring, and no test is taken for concrete compactness before waterproofing materials paving, the leakage passages will be formed in later stage due to failure of self-waterproofing by concrete, furthermore, roof leakage $\operatorname{appears}^{[1]}$ (as shown in Fig.1). 


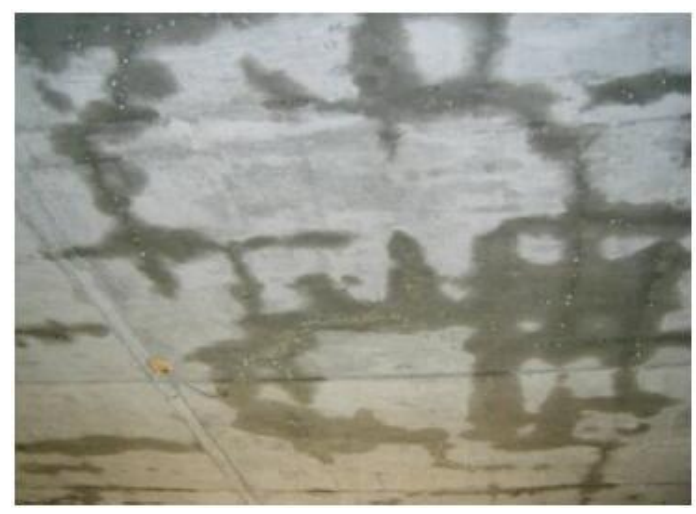

Fig.1 Leakage Due to Concrete Cracking

\section{Roof Leakage Due to Deformation Joint}

The deformation joint doesn't meet specification requirements and is blocked since there are inclusions in the joint, which forms a rigid structure and changes the performance of deformation joint to make the building settle in an unbalanced manner and crack on a part of walls; if the structural details of deformation joint is improper, for instance, the joint is brick-layed, with no arching treatment and additional waterproofing course executed at root and no buffering course on top cover, the seepage and leakage will occur on the waterproofing course when the cover is pulled to crack, hence, crack at roof of deformation joint and leakage on cover above joint occur to make the walls on both sides of the deformation joint to be dampened and leaked, as a result, stains, blackening and mildew can be seen on the walls. Fig. 2 demonstrates the situation of leak at some deformation joint on the industrial building.

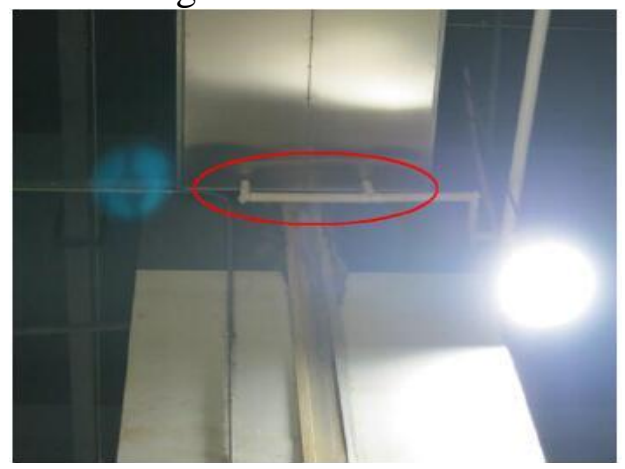

Fig.2 Leakage at Expansion Joint on Column of Industrial Building

\section{Leakage around Opening or Pipe on Roof}

No waterproofing treatment is executed for opening according to design details, and no waterproofing clay and silica gel is used at the steel plug; the rainwater cannot freely flow and might be easily accumulated as the preformed area around the opening is too small; the water is accumulated in a sunken space since no structural member is added around the opening; MEP embedded pipes are not at proper position, and the waterproofing course is completely damaged when it has to drill again; leakage also occurs as no waterproofing treatment is executed for edge overlap around the opening.

The root of pipe stretching out of the roof is not tightly sealed, the screeding course around pipe is not higher than the screeding course nearby, the flashing of waterproofing course is not high enough, etc., all of which will bring about leakage around pipe (as shown in Fig.3). 


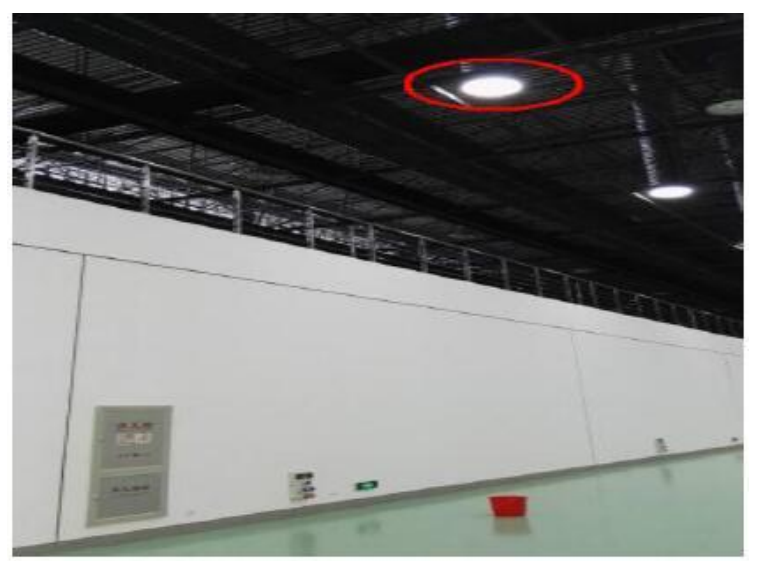

Fig.3 Leakage around Pipe Industrial Building

\section{Roof Leakage Due to Cracking or Blistering of Waterproofing Materials}

The roof panels on Industrial buildings have a large span, mostly, the waterproofing course needs to be overlapped and relevant bonding materials are needed at the overlap, however, such details are hard to reach the design standards thus leakage occurs. In addition, there are some main causes for cracking or blistering of waterproofing materials ${ }^{[2]}$ : firstly, rolls of low elongation are blindly used and the construction methods are improper, for instance, cracks along prefabricated roof will occur on the waterproofing course when the rolls are forcibly pulled during paving; secondly, whether the rolls can be largely well bonded with the base course depends on the flatness of mortar course, damage or blistering of materials will occur if the mortar course is uneven, and the rolls are not well bonded with the base course; thirdly, the rolls are directly bonded on the vertical walls of parapet, gable, etc, neither groove, nor press strip is arranged on flashing edge, hollowing and cracking will occur on the plastering course as the expansion and shrinkage degree of mortar and rolls are not identical, moreover, the rolls become extended at high temperature and fragile at low temperature, the edge of flashing rolls warps and expands during such repeated cycles; fourthly, workers do not observe regulations, and arbitrarily step on the waterproofing course during work, which destroys the flatness to make it crack and leak.

\section{Leakage at Root of Parapet}

Some parapet on concrete frame of industrial buildings is 240 thick brick wall. The parapet is at the internal corner of waterproofing joint where the waterproofing course is easily damaged and leakage easily occurs. The screeding course, plastering of parapet and flashing groove are not constructed at the same time with the screeding course on roof, the lower edge of flashing groove is not arched or sufficiently arched according to relevant regulations, the edge of rolls is not tightly sealed with only a few fixing points, the edge of sealing materials is partly separated, all of which will bring about the leakage on parapet ${ }^{[3]}$. In addition, poor verticality and flatness on the plaster of parapet, preformed groove on wall inconsistent with roof slope, inconsistent depth of flashing board in parapet, will also bring about leakage when the flashing board is partly separated with the plastering course due to thermal expansion, etc.

\section{Prevention and Control Measures against Roof Leakage}

\section{Prevention against Roof Leakage}

Control by Waterproofing Materials. Quality materials are the foundation and precondition for waterproofing $^{[4]}$. However, the good and the bad are intermingled in the market; the service life cannot be guaranteed when bad materials are used even with good construction practices. The roof is exposed in the sunshine, rain and snow for long term, the roof panels will extend or shrink with the temperature change day and night in different seasons, therefore, waterproofing materials of good durability, aging resistance, certain elaboration, good thermal resistance, e.g. polyester 
modified asphalt waterproofing rolls, PVC waterproofing rolls, EPDM waterproofing sheets or waterproofing asphalt felt and so on, should be first selected to prevent roof leakage due to cracking or blistering of waterproofing materials ${ }^{[5]}$.

Self-waterproofing by Concrete Structure. The self-waterproofing of concrete structure refers to the concrete resistance to water penetration, a measure of impermeability related to the compactness of concrete. The following 3 conditions shall be satisfied for good self-waterproofing of concrete slabs: firstly, the concrete shall have good impermeability; secondly, the post-pouring strip, construction joint and deformation joint of concrete slabs shall be properly treated without crack; thirdly, the concrete shall be compacted. Therefore, the waterproofing rolls shall not be paved unless concrete materials are strictly controlled, and concrete joints are properly treated to make the concrete structure self-resistant to water penetration.

Control during Work. The previous procedure shall inspected and handed over before work, in particular, the drainage slope shall be noted that accumulated water can be avoided after waterproofing treatment; it shall be checked whether the part around pipe out of roof, corner of parapet are coned and arched, mortar dots on concrete are cleaned, depressed points are repaired. Before large-area work, all details, e.g. eaves, roof flashing, deformation joint on roof, downspout on roof, pipe out of pipe, vertical inlet and outlet, shall be specially controlled and sealing materials are not omitted. JS waterproofing emulsion and polyurethane waterproofing paint can be used for cracks at pipe out of roof, downspout, and corner to guarantee the waterproofing quality at details.

In addition to these crucial preventive measures, the waterproofing team's selection and later-stage service shall also be strictly controlled. Based on investigation of several sites, $80 \%$ teams borrowed the qualification of waterproofing, the competence of teams could not be guaranteed, and so the quality performance of waterproofing works couldn't be achieved. Meanwhile, electrical equipments or appliances, e.g. green plants, solar heater, etc, shall not be erected on the roof after the building is handed over so as to prevent damage on waterproofing and drainage system on roof due to anchor bolts ${ }^{[6]}$.

\section{Control of Roof Leakage}

In principle, the control of roof leakage shall start with the treatment on roof, based on years of experience on site, the effect at leakage point by indoor treatment is not good and it cannot solve the root problem. Since hollowing easily occurs on waterproofing rolls, the water channel is naturally formed under rolls, and the water will flow to any direction when it enters from the leakage point, thus, more leakage points will occur and it cannot be solved with only one leakage point blocked.

As for inaccessible roof, while the waterproofing course is exposed, the quality of waterproofing rolls shall be checked, e.g. tear due to incompliant and base material or poor flexibility at low temperature, the rolls with these problems shall be completely removed and reworked; when the materials are good, it shall focus on the details to check the overlapped edge of rolls, edge of parapet, pipe out of roof, downspout, crack on parapet, foundation of other equipments, for instance, the overlapped edge of rolls can be melted and reworked again, accidental cracks can be repaired by proper materials, downspout, wall corner and roof pipe can be chiseled and treated according to technical regulations.

As for accessible roof, while the roof is rigid concrete course or decorative tiles, it is required to check the parapet, drainage ditch, pipe out of roof and foundation of other equipments to confirm whether there is possibility of penetration; the part of penetration can be chiseled for check and treatment, especially the waterproofing treatment at root of walls. Based on experience of many projects, the leakage problem can be basically and well solved by above checks and treatment.

\section{Conclusion}

All aspects, including design, construction, supervision, operation management, are involved from commencement of a building to its service. From the above analysis, the leakage will occur on a building due to many causes, such as materials, design omission, incompliant work, improper supervision, and improper service in later stage. Therefore, it is required to strictly observe national 
standards and regulations, adopt qualified materials, employ professional workers, and regulate service in later stage to reduce roof leakage, extend the service life of buildings and promote the sustainable development of the construction industry.

\section{References}

[1] Pan Li. Consideration about The Crack Problem of Concrete Structures [J]. Industrial Construction, 2000, 05:62-65.

[2] NI Yunguang. Discussion on the Reason Analysis and Countermeasures of Water Leakage in Steel Structure Workshop [J]. Science \& Technology Information, 2012, 03:468.

[3] Tan Liguo, Liu Yuhong, Guo Chunyan, Huang Xiaojia. The Causes and Countermeasures for Rainwater Penetration through Roofs of Steel Structure Factory Buildings in Northern Region [J]. China Water \& Wastewater, 2011, 12:18-22.

[4] Liu Kun, Hou Chuan. Analysis on the Causes of Roof Leakage [J]. Shanxi Architecture, 2006, 01:143-144.

[5] Ye Linbiao. Status, Reasons, Damages and Prevention of Water Leakage in Building [J]. Construction Technology, 2008, 04:1-3.

[6] Sun Lixin, Yang Zhiyong. The Prevention and Treatment of Roof Leakage [J]. Sci-Tech Information Development \& Economy, 2010, 08:212-213. 